\title{
MO-CCCCTA-Based Floating Positive and Negative Inductors and Their Applications
}

\author{
Neeta Pandey, Rishik Bazaz, and Rahul Manocha \\ Department of Electronics and Communications Engineering, Delhi Technological University, Delhi 110042, India \\ Correspondence should be addressed to Neeta Pandey, n66pandey@rediffmail.com \\ Received 31 March 2011; Revised 19 June 2011; Accepted 25 June 2011 \\ Academic Editor: Muhammad Taher Abuelma'atti \\ Copyright () 2011 Neeta Pandey et al. This is an open access article distributed under the Creative Commons Attribution License, \\ which permits unrestricted use, distribution, and reproduction in any medium, provided the original work is properly cited.
}

This paper introduces a floating inductance simulation using multiple output current controlled current conveyer transconductance amplifier (MO-CCCCTA). The simulated inductor retains minimum requirement of passive elements as only one-grounded capacitance is used for one inductor. PSPICE simulation has been done and included to ensure the validity of the approach. A few applications have also been included to substantiate the usability of the proposed circuit.

\section{Introduction}

The current mode (CM) have received major consideration in the recent past owing to their various advantages like higher bandwidth, greater linearity, higher dynamic range, and lower power consumption which makes them a better candidate for analog circuits than their voltage mode counterparts. Furthermore, since signals are represented by current, a much lower voltage is required as compared with the voltage-mode signal processing. This makes the current mode circuits suitable for low-voltage designs. With recent introduction of second-generation current controlled conveyors (CCCII) [1], current conveyor transconductance amplifier (CCTA) [2], and MO-CCCCTA [3], current conveyors' applications have been extended to the domain of electronically adjustable functions.

Despite the fact that a spiral inductor can be realised in VLSI circuits, the need for improvement cannot be ignored. It has many disadvantages, namely, space usage, cost, and robustness. Many analog functional blocks (AFBs) have already been reported for active simulation of inductors to extract benefits of passive prototypes [4-25]. These AFBs include Operational Transconductance Amplifiers (OTAs) $[4,8,18]$, Current Feedback Opamps (CFOAs) [20], current conveyors and current controlled conveyors [7-12, 14, 15, 18, 19, 22-24], Operational Transresistance Amplifier [13], Current Differencing Buffered Amplifier [16], Current
Backward Transconductance Amplifier [17], Differential Difference Current Conveyor [21], and Voltage Differencing Differential Input Buffered Amplifiers [25]. The study of floating inductor simulators $[4,7-11,14-25]$ shows that the circuits suffer from one or more disadvantages: use of more than one active element $[4,7-11,14,15,18-20,22-$ 25], overuse of passive elements [7, 9-11, 16-22], lack of electronic tunability $[7,9-11,16,19-22]$, and use of floating capacitance $[6-11,14,15,21,22]$.

Negative inductance plays a significant role in cancellation as well as compensation of parasitic inductances. Actively simulated negative inductors have various applications

(i) in microwave circuits for impedance matching;

(ii) in compensation of bond wire in high-speed/lowpower integrated circuits (ICs) because of reduced noise margin.

Some active realisation of negative inductance has also been reported in the literature $[4,17,18,23,24]$. These too suffer from the weaknesses as enumerated earlier. The magnitude of both the inductors is linearly proportional to the frequency in both cases. It is the phase which differentiates the two. The positive inductor has a phase of $+90^{\circ}$, while the negative inductor has a phase of $-90^{\circ}$. MO-CCCCTA is a modified version of earlier introduced 


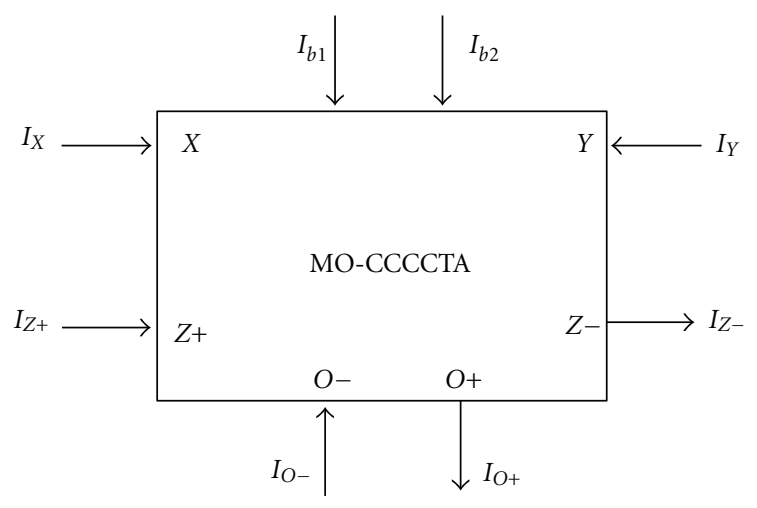

Figure 1: The functional symbol of MO-CCCCTA.

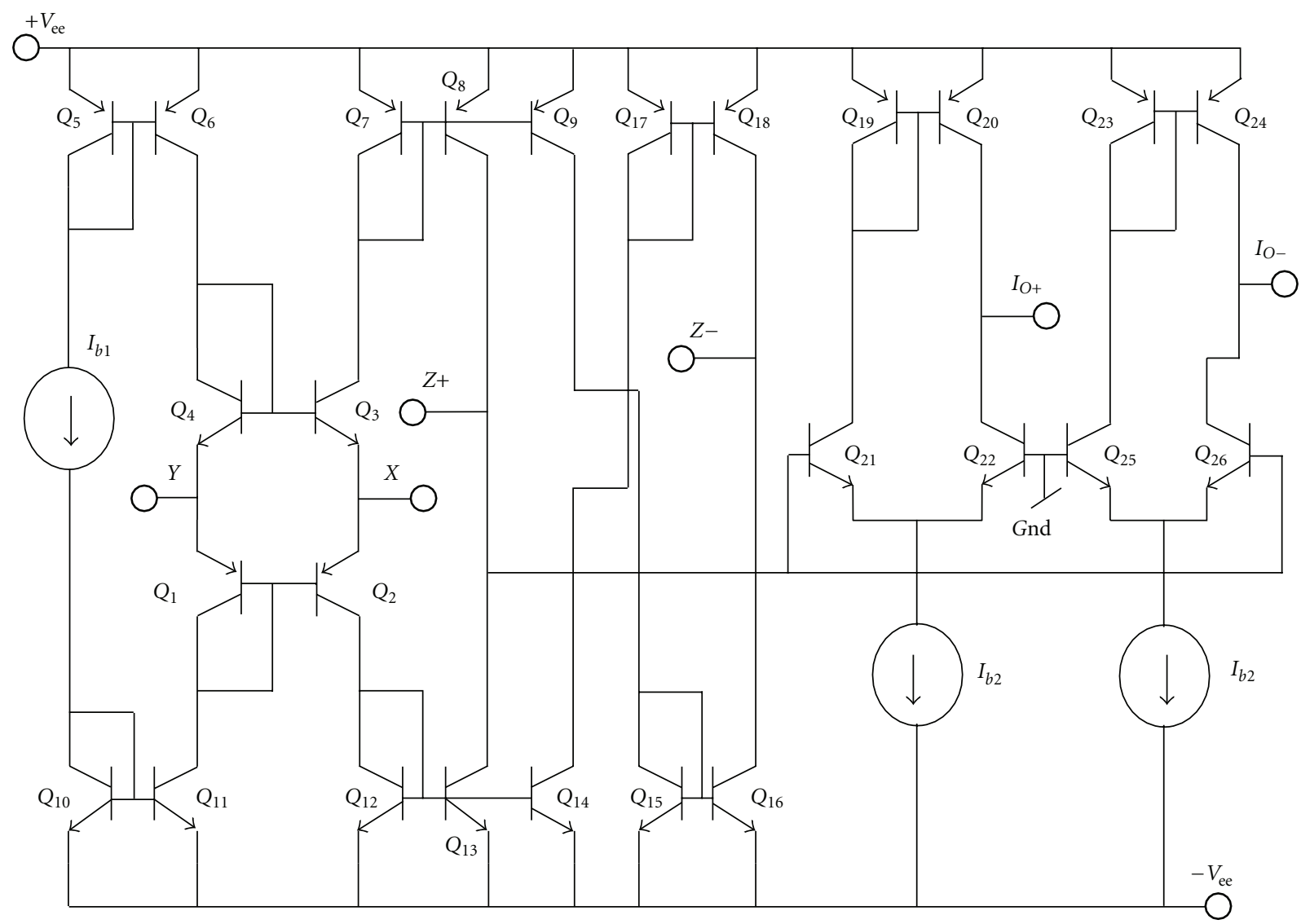

FIgURE 2: A possible bipolar implementation of the MO-CCCCTA.

CCTA and CCCII. MO-CCCCTA has been employed owing to the various advantages such as output current gain controllability, resistorlessness, and compactness in chip area.

In this paper, we present electronically controllable floating inductance simulations using MO-CCCCTA as active component. The circuit construction comprises only single MO-CCCCTA block and a grounded capacitor, which is suited for IC fabrication. The inductor value can be electronically tuned by input bias currents of the MO-CCCCTA. The performances of the proposed circuits are simulated with
PSPICE, and they showed good agreement with ideal passive counterparts. Some applications such as fifth order low-pass filter, RLC band-stop filter and inductance nullifying circuit, are also given to demonstrate the usefulness of the proposed element.

\section{Functional Block Description}

The MO-CCCCTA as shown in Figure 1 is characterized by the port relations [3] of (1). The MO-CCCCTA has a finite 


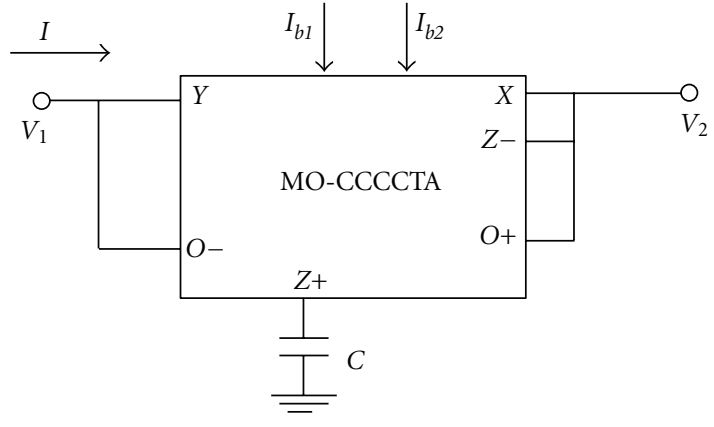

FIgUre 3: Proposed floating positive inductance.

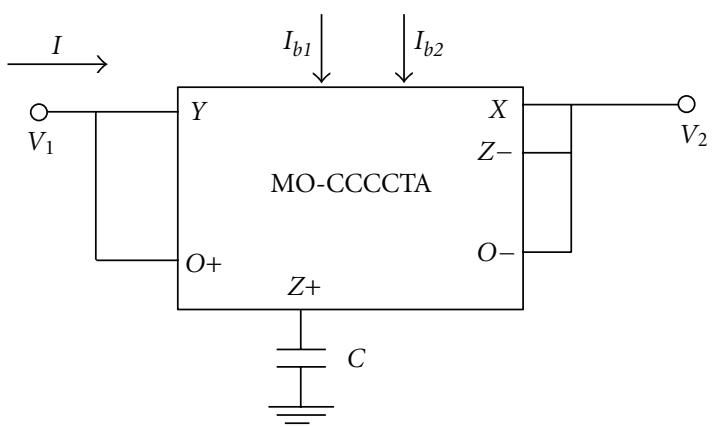

FIGURE 4: Proposed floating negative inductance.

input resistance $R_{X}$ at the $X$ input terminal and an additional transconductance $g_{m}$ amplifier in the output side

$$
\left[\begin{array}{c}
I_{Y} \\
V_{X} \\
I_{Z_{ \pm}} \\
I_{O_{ \pm}}
\end{array}\right]=\left[\begin{array}{cccc}
0 & 0 & 0 & 0 \\
R_{X} & 1 & 0 & 0 \\
\pm 1 & 0 & 0 & 0 \\
0 & 0 & \pm g_{m} & 0
\end{array}\right]\left[\begin{array}{c}
I_{X} \\
V_{Y} \\
V_{Z} \\
V_{O}
\end{array}\right] .
$$

The parasitic resistance $R_{X}$ and the transconductance $g_{m}$ can be controlled by bias currents $I_{b 1}$ and $I_{b 2}$, respectively. A BJT-based MO-CCCCTA is illustrated in Figure 2, and the intrinsic resistance $\left(R_{X}\right)$ and transconductance $\left(g_{m}\right)$ are expressed as

$$
R_{X}=\frac{V_{T}}{2 I_{b 1}}, \quad g_{m}=\frac{I_{b 2}}{2 V_{T}},
$$

where $I_{b i}(i=1,2)$ and $V_{T}$ are the bias currents and the thermal voltage, respectively.

\section{Inductor Design}

The proposed positive floating inductor is shown in Figure 3, and its negative configuration is shown in Figure 4. Using the routine analysis of the circuit, the impedance may be calculated as

$$
Z_{\text {in }}=\frac{s R_{X} C}{g_{m}} .
$$

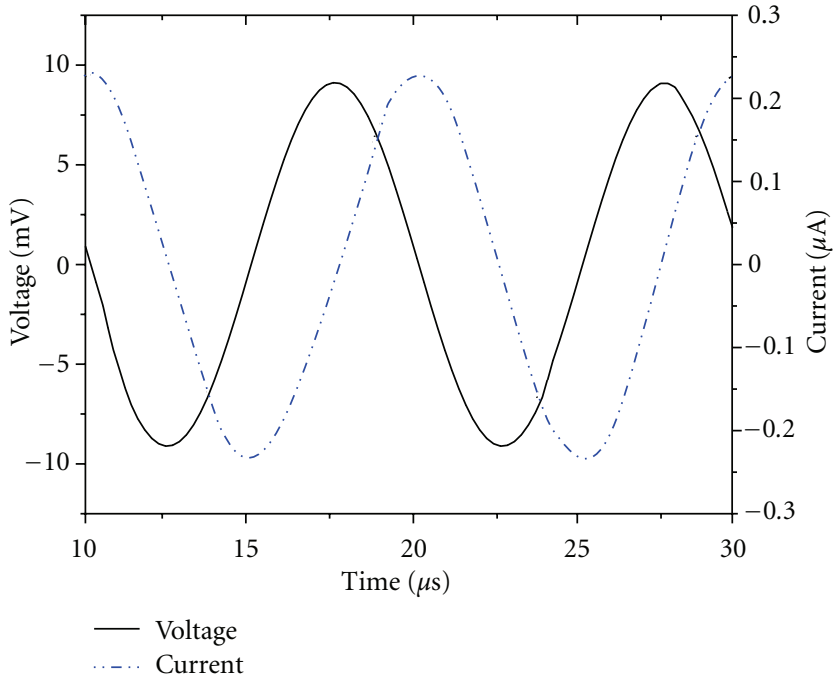

FIgURE 5: Transient response for positive inductor.

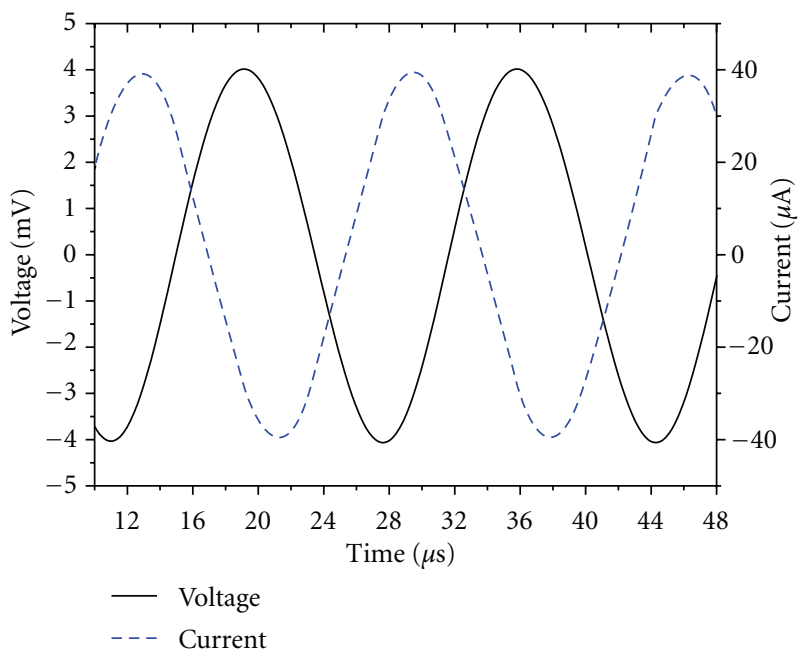

FIgURE 6: Transient response for negative inductor.

The equivalent positive inductance value in terms of bias current is

$$
L_{\mathrm{eq}}=\frac{C V_{T}^{2}}{I_{b 1} I_{b 2}} .
$$

Similarly, the equation for negative inductance is

$$
L_{\mathrm{eq}}=-\frac{C V_{T}^{2}}{I_{b 1} I_{b 2}} .
$$

3.1. Effect of Nonidealities. The frequency performance of the inductor may deviate from the ideal ones due to nonidealities. The nonidealities may be categorized in two groups: transfer errors and parasites. The first comes from transfer errors in internal current and voltage transfers of 


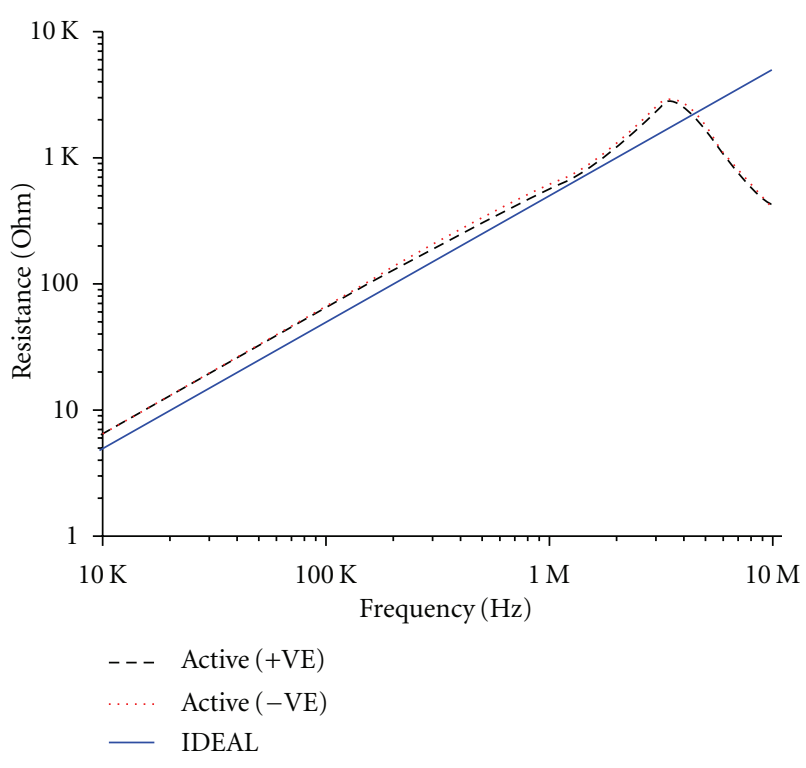

FIGURE 7: Magnitude plot for proposed floating inductor.

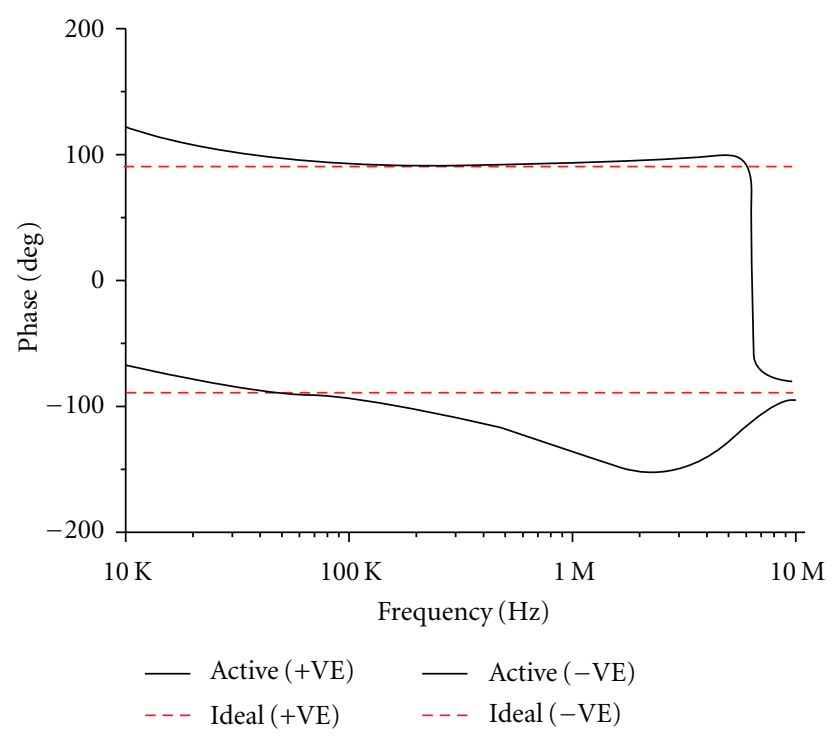

FIGURE 8: Phase plot for proposed inductor.

MO-CCCCTA and their frequency dependence and can be written as

$$
\left[\begin{array}{c}
I_{Y} \\
V_{X} \\
I_{Z \pm} \\
I_{O \pm}
\end{array}\right]=\left[\begin{array}{cccc}
0 & 0 & 0 & 0 \\
R_{X} & \beta & 0 & 0 \\
\pm \alpha & 0 & 0 & 0 \\
0 & 0 & \pm \gamma g_{m} & 0
\end{array}\right]\left[\begin{array}{c}
I_{X} \\
V_{Y} \\
V_{Z} \\
V_{O}
\end{array}\right],
$$

where the coefficients $\beta=1-\varepsilon_{v}, \alpha_{ \pm}=1-\varepsilon_{i \pm} ; \varepsilon_{v}$ and $\varepsilon_{i \pm}$ denote voltage and current tracking errors from $Y$ to $X$ terminal and $X$ to $Z$ terminal, respectively. The coefficient $\gamma$ denotes current gain from $Z$ terminal to $O$ terminal. The second group of nonidealities comes from parasites of MO-CCCCTA comprising of resistances and capacitances

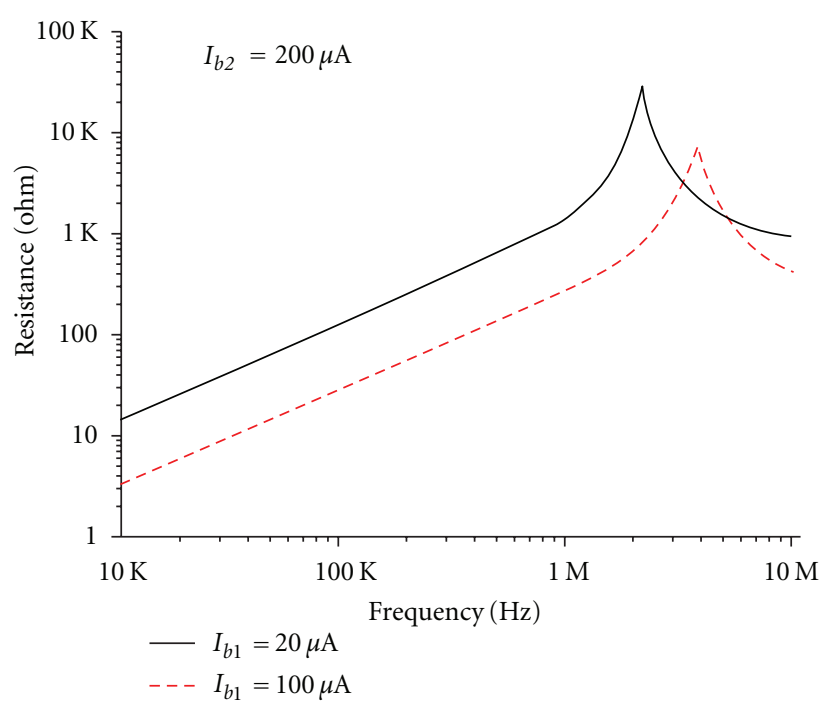

FIGURE 9: Variation of impedance with $I_{b 1}$.

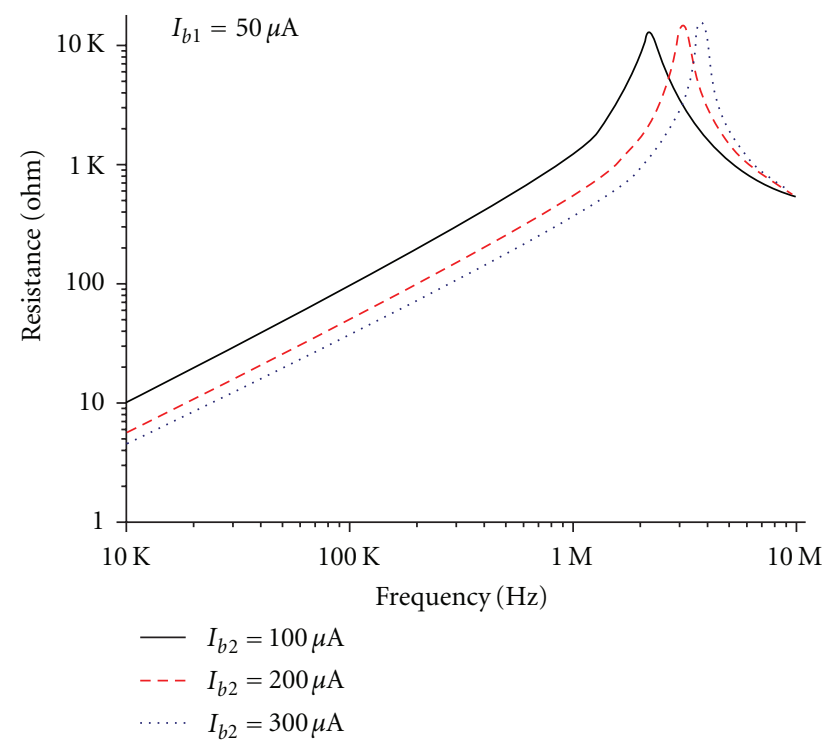

FIgURE 10: Variation of impedance with $I_{b 2}$.

connected in parallel at terminals $Y, Z$, and $O$ (i.e., $R_{Y}, C_{Y}$, $\left.R_{Z}, C_{Z}, R_{O}, C_{O}\right)$. The effects of these parasites on inductor behaviour depend strongly on circuit topology. In the presence of these parasites, the capacitor $C$ in circuits of Figures 3 and 4 modifies to $C / / C_{Z} / / R_{Z}$. Considering the nonidealities outlined above, (4) and (5) modify, respectively to

$$
\begin{gathered}
s L_{\mathrm{eq}}=\frac{\left(s C_{\mathrm{eq}}+G_{Z}\right) V_{T}^{2}}{\alpha \gamma I_{b 1} I_{b 2}}, \\
s L_{\mathrm{eq}}=-\frac{\left(s C_{\mathrm{eq}}+G_{Z}\right) V_{T}^{2}}{\alpha \gamma I_{b 1} I_{b 2}},
\end{gathered}
$$

where $C_{\mathrm{eq}}=C / / C_{Z}$ and $G_{Z}=1 / R_{Z}$. 


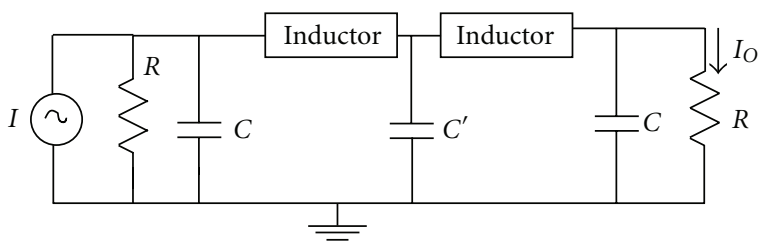

FIgURE 11: 5th order low pass filter.

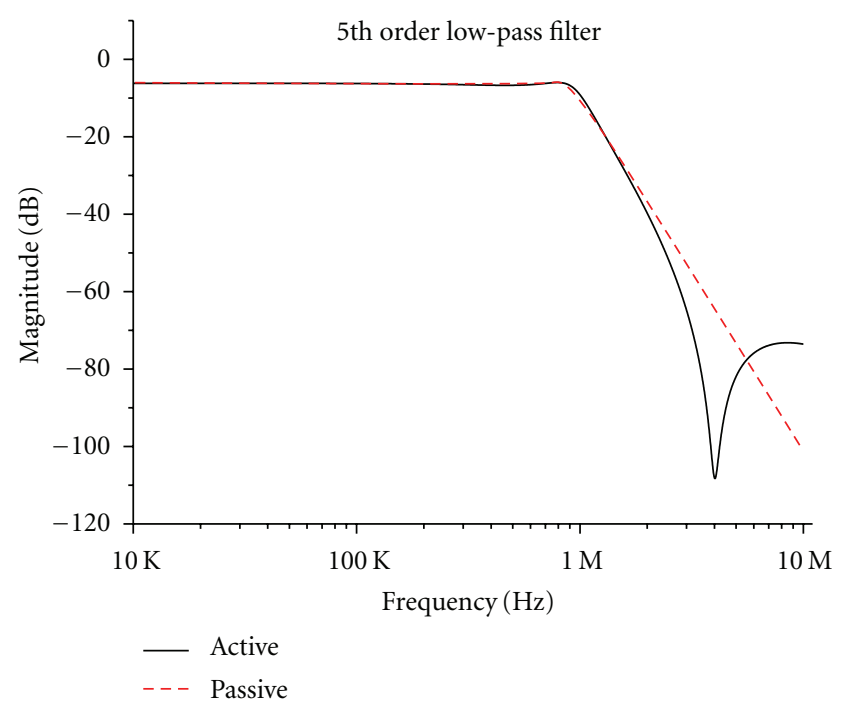

FIgURE 12: Magnitude response of 5th order filter.

It may be noted that the impedance value deviates from the ideal one due to nonunity values of $\alpha, \beta$, and $\gamma$. The values of $\alpha, \beta$, and $\gamma$ are simulated to, respectively, as $0.973,0.999$, and 0.998 . The maximum operating frequency will be influenced by parasitic resistance at $Z$ port as the parasitic capacitance at $Z$ port may be accommodated in external capacitor. The parasitic resistances and capacitances for MO-CCCCTA are simulated to be $R_{Y}=749 \mathrm{k} \Omega, C_{Y}=$ $6.89 \mathrm{pF} ; R_{Z}=789 \mathrm{k} \Omega, C_{Z}=4.03 \mathrm{pF} ; R_{O}=1.70 \mathrm{M} \Omega$, $C_{O}=3.3 \mathrm{pF}$, respectively. It may be noted that by selecting $C \gg C_{Z}$, the effect of parasitic capacitance may practically be ignored. However, a zero $\left(1 / R_{Z} C_{\text {eq }}\right)$ is introduced in impedance of (7) and (8) which limits the lower frequency operation.

The current and voltage transfer functions, apart from having nonunity values, also have poles at high frequencies. However, the maximum frequency of operation will be limited by poles of voltage $\left(f_{\beta}\right)$ and current $\left(f_{\alpha}, f_{\gamma}\right)$ and transfers which are simulated to be $70.09 \mathrm{MHz}, 33.7 \mathrm{MHz}$, and $78.85 \mathrm{MHz}$ for the MO-CCCCTA of Figure 2. The effect can, however, be ignored if the operating frequencies are chosen sufficiently smaller than voltage and current transfer pole frequencies of the MO-CCCCTA.

3.2. Comparison. Survey of the literature till date on floating inductors reveals that two or more active blocks are required for implementation except those available in $[16,17,21]$, where a single active block is required as that of presented work. It reveals that our work is comparable with the works of $[16,17,21]$. Hence we compare our work with $[16,17,21]$.

\section{Requirement of Passive Components:}

(1) The total number of passive components is more than one in $[16,17,21]$, whereas the proposed topologies use a single passive component.

(2) Floating passive components are used in [21] which is not considered good from IC implementation viewpoint.

\section{Electronic Tunability:}

(1) There is no electronic tunability in $[16,21]$.

(2) Though tunability is available in [17] through one bias current, the proposed topology has more flexibility as the inductance value can be tuned via two bias currents of MO-CCCCTA.

\section{Simulation Results and Discussions}

To validate the theoretical predictions, the proposed circuits are simulated with SPICE using schematic of MO-CCCCTA, as given in Figure 2, and PR100N and NR100N bipolar transistors [26]. The DC supply voltage of $1.5 \mathrm{~V}$ is used. The bias current values are $I_{b 1}=50 \mu \mathrm{A}$ and $I_{b 2}=200 \mu \mathrm{A}$ for all the simulations. Figures 5 and 6 show the transient 


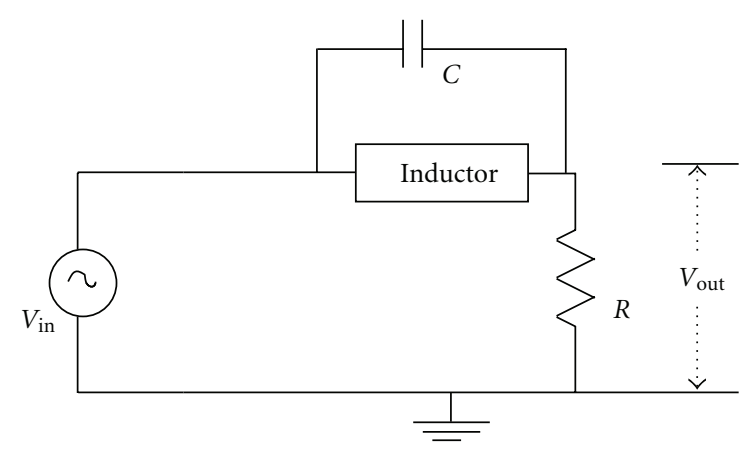

FIgURE 13: Band-stop filter.

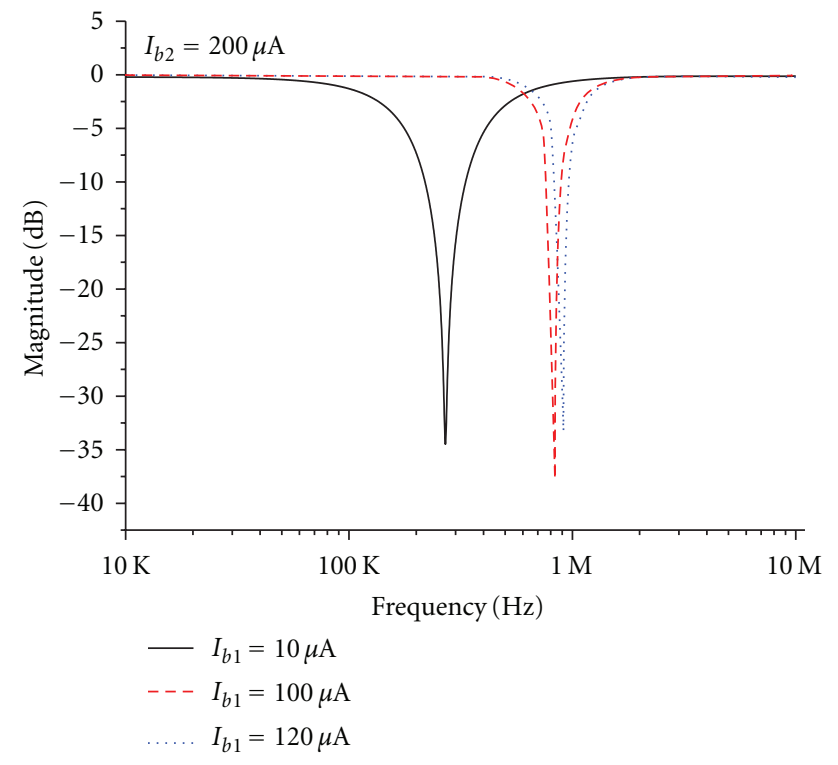

(a)

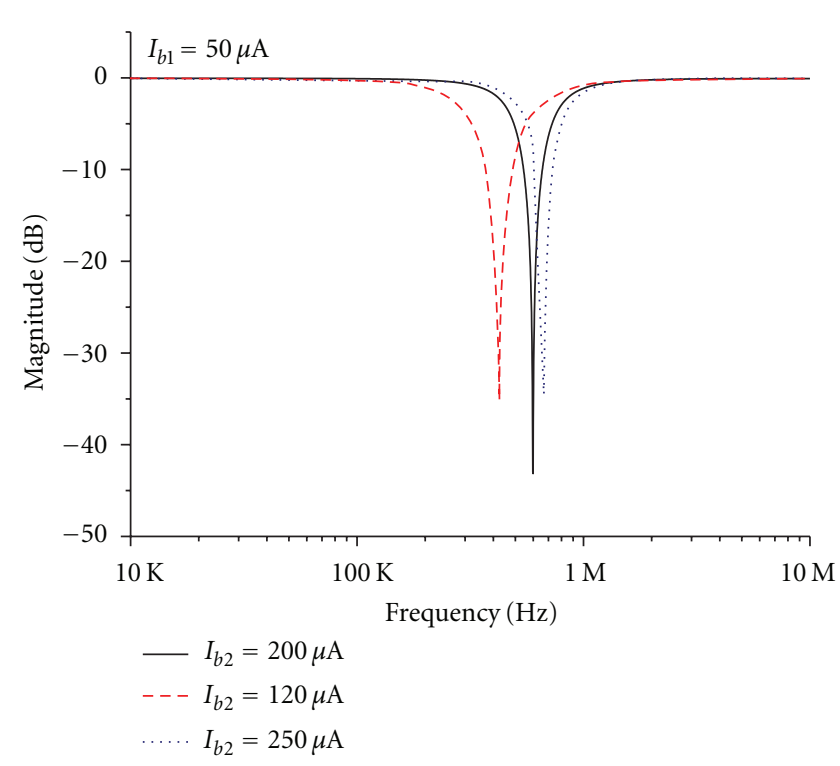

(b)

FIgURE 14: Magnitude response of band-stop filter.

responses obtained from the proposed simulated inductors. The impedances of the proposed circuit with respect to frequency, which are compared to ideal inductor, are also shown in Figure 7. It can be seen that the circuit can be used up to several megahertz. At a high-frequency range, the proposed inductors degrade their performances. Figure 8 shows impedance phase plot.

Parametric simulation by varying the two bias currents was also done. Figures 9 and 10 show the variation in impedance magnitude for different $I_{b 1}$ and $I_{b 2}$, respectively. It is confirmed that the simulated inductance values can be adjusted by corresponding input bias currents.

\section{Applications}

To illustrate the use of proposed floating inductor, various applications like band-stop filter and fifth order low-pass filter were simulated. All the circuits have been simulated using PSPICE. The passive RLC 5th order low-pass filter as shown in Figure 11 was taken as reference. The circuits are designed for half power frequency $\omega_{-3 \mathrm{~dB}}=10 \mathrm{Mrad} / \mathrm{s}$ or $1.59 \mathrm{MHz}$. Then after scaling the different component values are $C=$ $475.2 \mathrm{pF}$ and $C^{\prime}=1.538 \mathrm{nF}$. The capacitance required in the floating inductance block is $0.73 \mathrm{nF}$ each. Each circuit is denormalized by source resistance $R=R_{X}$, which is realized using the same MO-CCCCTA AFB. The magnitude response of the proposed circuit has been shown in Figure 12. The simulated results show close conformity with the theoretical results. The magnitude response of the active low-pass filter closely follows its passive implementation.

A band-stop filter with center frequency of $600 \mathrm{KHz}$ was also simulated. Time domain response was also carried out. The filter model is shown in Figure 13, and its magnitude response is shown in Figure 14. The input signal comprised of three frequencies of $10 \mathrm{KHz}, 100 \mathrm{KHz}$, and $600 \mathrm{KHz}$. Signal amplitude was $10 \mathrm{mV}$ each. The transient response with its spectrum for input and output is shown in Figure 15, which clearly shows that the $600 \mathrm{KHz}$ signal is significantly attenuated. 

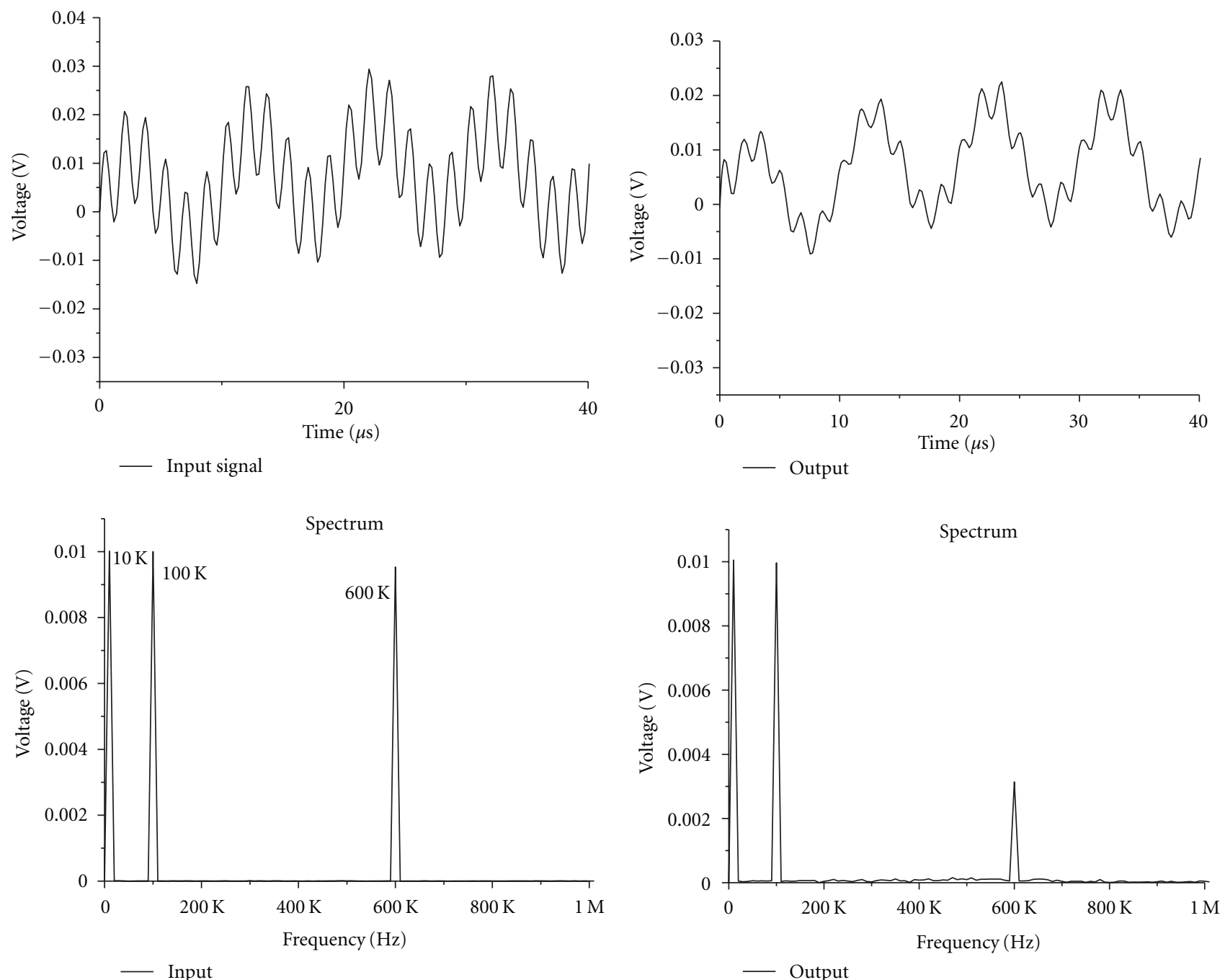

(a)

(b)

FIGURE 15: Transient response and its spectrum (a) input and (b) output.

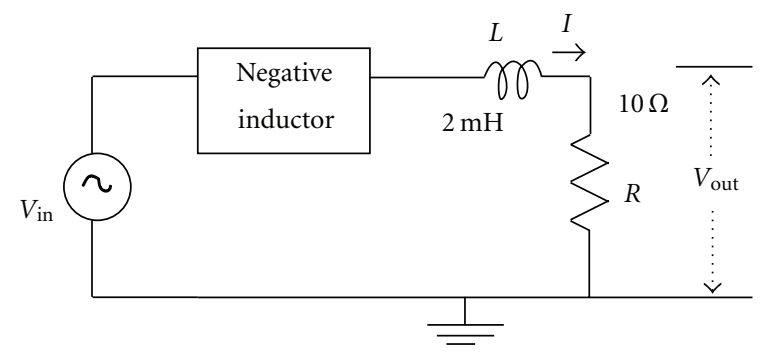

FIGURE 16: Inductance-nullifying circuit.

The third application is the inductance compensation circuit as shown in Figure 16. The transient response has been shown in Figure 17. It can be observed that the positive inductance in the circuit has been nullified by the simulated negative floating inductor as there is very low phase lag between current and voltage.

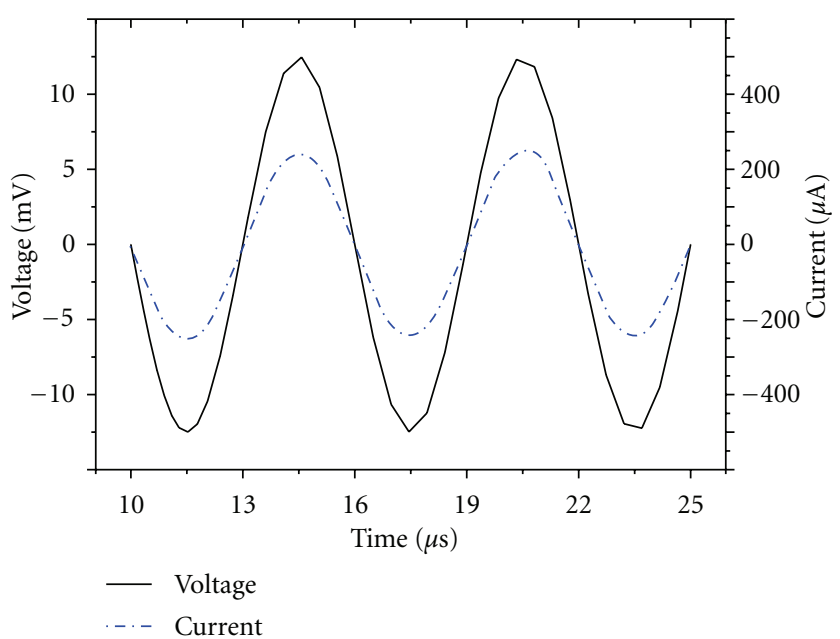

FIGURE 17: Transient response of inductor-nullifying circuit. 


\section{Conclusion}

The novel floating positive and negative inductors with electronic tunability employing only single MO-CCCCTA have been introduced in this paper. The proposed inductors can be easily and widely tuned using bias current values. The simulated results of active and passive circuits match to a wide range of operation. The proposed inductors have been employed in construction of low-pass filter, band-stop filter and inductance-nullifying circuit. PSPICE simulation has been used to verify the functionality of various circuits.

\section{References}

[1] A. Fabre, O. Saaid, F. Wiest, and C. Boucheron, "High frequency applications based on a new current controlled conveyor," IEEE Transactions on Circuits and Systems I, vol. 43, no. 2, pp. 82-91, 1996.

[2] W. Jaikla, P. Silapan, C. Chanapromma, and M. Siripruchyanun, "Practical implementation of CCTA based on commercial CCII and OTA," in International Symposium on Intelligent Signal Processing and Communication Systems (ISPACS '08), February 2009.

[3] M. Siripruchyanun and W. Jaikla, "Current controlled current conveyor transconductance amplifier (CCCCTA): a building block for analog signal processing," Electrical Engineering, vol. 90, no. 6, pp. 443-453, 2008.

[4] W. Petchmaneelumka, "OTAs-based positive/negative floating inductance simulator," in Proceedings of the International Multi Conference of Engineers and Computer Scientists (IMES2009), vol. 2, Hong Kong, March 2009.

[5] M. T. Abuelma'atti and H. A. Alzaher, "Active-only sinusoidal oscillator," Microelectronics Journal, vol. 29, no. 7, pp. 461-464, 1998.

[6] A. T. Hanachayanont and A. Payne, "CMOS floating active inductor and its applications to bandpass filter and oscillator designs," IEE Proceedings: Circuits, Devices and Systems, vol. 147, no. 1, pp. 42-48, 2000.

[7] W. Kiranon and P. Pawarangkoon, "Floating inductance simulation based on current conveyors," Electronics Letters, vol. 33, no. 21, pp. 1748-1749, 1997.

[8] M. Higashimura and Y. Fukui, "Simulation of lossless floating inductance using two current conveyors and an operational transconductance amplifier," International Journal of Electronics, vol. 66, no. 4, pp. 633-638, 1989.

[9] G. Ferri, N. C. Guerrini, and M. Diqual, "CCII-based floating inductance simulator with compensated series resistance," Electronics Letters, vol. 39, no. 22, pp. 1560-1562, 2003.

[10] V. Singh, "Active RC single-resistance-controlled lossless floating inductance simulation using single grounded capacitor," Electronics Letters, vol. 17, no. 24, pp. 920-921, 1981.

[11] P. V. A. Mohan, "Grounded capacitor based grounded and floating inductance simulation using current conveyors," Electronics Letters, vol. 34, no. 11, pp. 1037-1038, 1998.

[12] H. Kuntman, M. Gülsoy, and O. Çiçekoglu, "Actively simulated grounded lossy inductors using third generation current conveyors," Microelectronics Journal, vol. 31, no. 4, pp. 245250, 2000 .

[13] U. Cam, F. Kacar, O. Çiçekoglu, H. Kuntman, and A. Kuntman, "Novel grounded parallel immittance simulator topologies employing single OTRA," AEU-International Journal Electronics and Communications, vol. 57, no. 4, pp. 287-290, 2003.
[14] I. A. Khan and M. H. Zaidi, "A novel ideal floating inductor using translinear conveyors," Active and Passive Electronic Components, vol. 26, no. 2, pp. 87-89, 2003.

[15] S. Minaei, E. Yuce, and O. Çiçekoglu, "Lossless active floating inductance simulator," in Proceedings of the 3rd IEEE International Workshop on Electronic Design, Test and Applications (DELTA '06), pp. 332-335, Kuala Lumpur, Malaysia, January 2006.

[16] M. Gülsoy and O. Çiçekoğlu, "Lossless and lossy synthetic inductors employing single current differencing buffered amplifier," IEICE Transactions on Communications, vol. E88-B, no. 5, pp. 2152-2155, 2005.

[17] M. Sagbas, "Component reduced floating $\pm L, \pm C$ and $\pm R$ simulators with grounded passive components," AEU-International Journal of Electronics and Communications, vol. 65, no. 10, pp. 794-798, 2011.

[18] M. Sagbas, U. E. Ayten, H. Sedef, and M. Koksal, "Floating immittance function simulator and its applications," Circuits, Systems, and Signal Processing, vol. 28, no. 1, pp. 55-63, 2009.

[19] E. Yuce, O. Çiçekoglu, and S. Minaei, "CCII-based grounded to floating immittance converter and a floating inductance simulator," Analog Integrated Circuits and Signal Processing, vol. 46, no. 3, pp. 287-291, 2006.

[20] E. Yuce, "Novel lossless and lossy grounded inductor simulators consisting of a canonical number of components," Analog Integrated Circuits and Signal Processing, vol. 59, no. 1, pp. 7782, 2009.

[21] E. Yuce, "New low component count floating inductor simulators consisting of a single DDCC," Analog Integrated Circuits and Signal Processing, vol. 58, no. 1, pp. 61-66, 2009.

[22] S. Minaei, E. Yuce, and O. Çiçekoglu, "A versatile active circuit for realising floating inductance, capacitance, FDNR and admittance converter," Analog Integrated Circuits and Signal Processing, vol. 47, no. 2, pp. 199-202, 2006.

[23] E. Yuce, "On the realization of the floating simulators using only grounded passive components," Analog Integrated Circuits and Signal Processing, vol. 49, no. 2, pp. 161-166, 2006.

[24] E. Yuce, S. Minaei, and O. Çiçekoglu, "Resistorless floating immittance function simulators employing current controlled conveyors and a grounded capacitor," Electrical Engineering, vol. 88, no. 6, pp. 519-525, 2006.

[25] D. Prasad, D. R. Bhaskar, and K. L. Pushkar, "Realization of new electronically controllable grounded and floating simulated inductance circuits using voltage differencing differential input buffered amplifiers," Active and Passive Electronic Components, vol. 2011, Article ID 101432, 8 pages, 2011.

[26] D. R. Frey, "Log-domain filtering: an approach to currentmode filtering," IEE Proceedings, Part G, vol. 140, no. 6, pp. 406-416, 1993. 

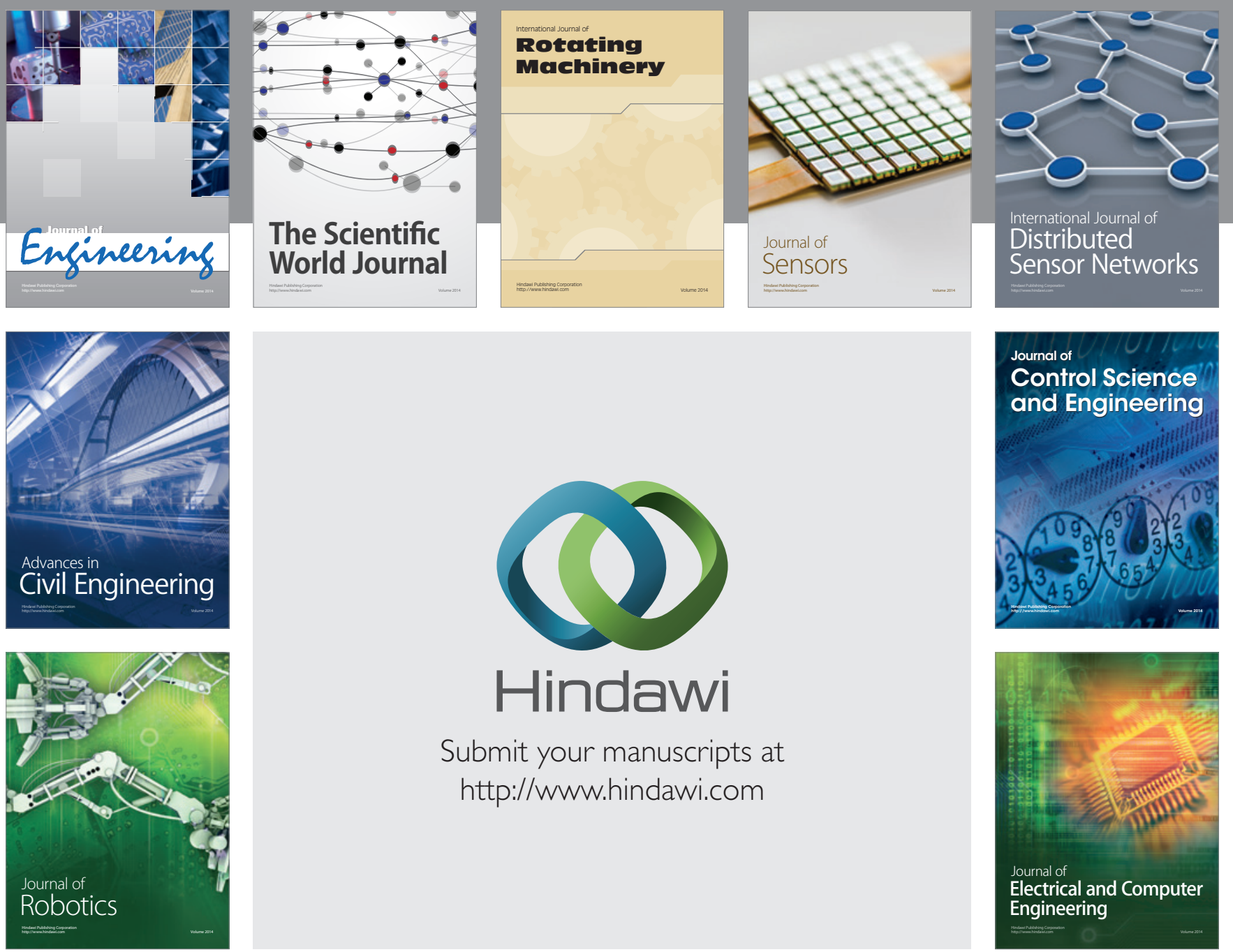

Submit your manuscripts at

http://www.hindawi.com
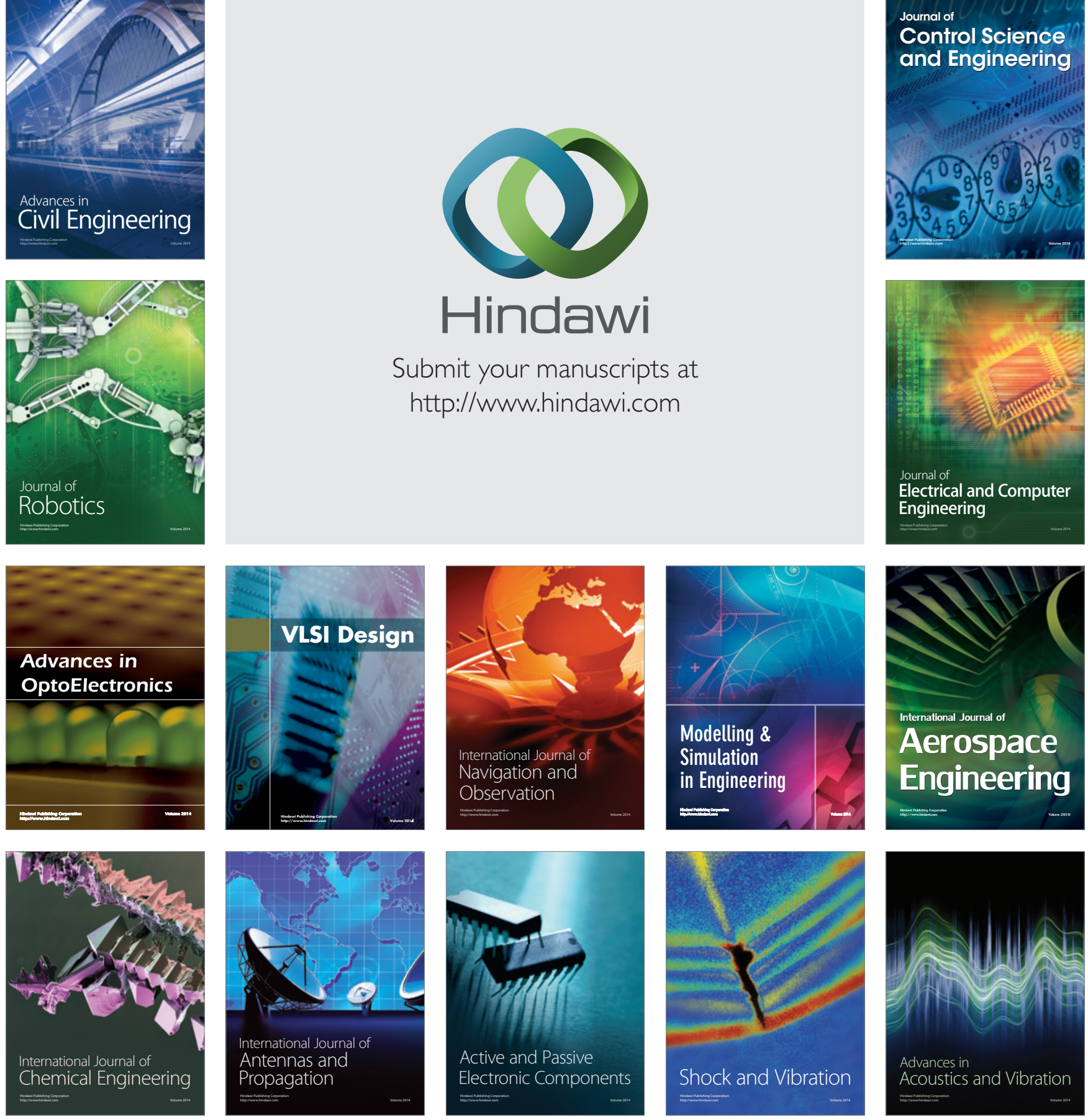